\title{
Tetrathiafulvalene-Based Helicene Ligand in the Design of Dysprosium Field-Induced Single-Molecule Magnet
}

\author{
Fabrice Pointillart, ${ }^{* a}$ Jiang-Kun Ou-Yang, ${ }^{a}$ Guglielmo Fernandez Garcia, ${ }^{\text {ab }}$ Vincent Montigaud, Jessica \\ Flores Gonzalez, ${ }^{\mathrm{a}}$ Rémi Marchal, ${ }^{\mathrm{a}}$ Ludovic Favereau, ${ }^{\mathrm{a}}$ Federico Totti, ${ }^{\mathrm{b}}$ Jeanne Crassous, ${ }^{{ }_{\mathrm{a}}}$ Olivier Ca- \\ dor, ${ }^{a}$ Lahcène Ouahab, ${ }^{a}$ Boris Le Guennic ${ }^{* a}$
${ }^{a}$ Univ Rennes, CNRS, ISCR (Institut des Sciences Chimiques de Rennes) - UMR 6226, 35000 Rennes, France \\ ${ }^{\mathrm{b}}$ Department of Chemistry «Ugo Schiff » and INSTM RU, University of Florence, 50019 Sesto Fioren- \\ tino, Italy.
}

\begin{abstract}
The design of a coordination complex which involves a ligand combining both a tetrathiafulvalene core and helicene fragment was achieved thanks to the reaction between the new 2-\{1-[2-methyl[6]helicene]-4,5-[4,5-bis(propylthio)tetrathiafulvalenyl]-1H-benzimidazol-2-yl $\}$ pyridine ligand $(\mathbf{L})$ and the Dy(hfac $)_{3} \cdot 2 \mathrm{H}_{2} \mathrm{O}$ metallo precursor. Magnetic investigations showed a field-induced Single-Molecule Magnet (SMM) behavior under an applied magnetic field of 1000 Oe for $\left[\mathrm{Dy}(\mathrm{hfac})_{3}(\mathbf{L})\right] \cdot 0.5 \mathrm{CH}_{2} \mathrm{Cl}_{2}$ while experimental oriented single crystal magnetic measurements allowed for the determination of the magnetic anisotropy orientation. The magnetic behavior was rationalized based on ab initio CASSCF/SI-SO calculations. This redox-active chiral field-induced SMM paves the route for designing switchable multi-properties SMMs.
\end{abstract}

Chemists are working hand in hand with physicists to design Single-Molecule Magnets (SMMs) displaying magnetic bistability at temperatures as high as possible. Recently a mononuclear Dy ${ }^{\text {III }}$-SMM highlighted a blocking temperature of $60 \mathrm{~K}^{1-3}$ jump-starting this kind of molecular objects suitable for potential applications in high-density data storage, quantum computing and spintronics. ${ }^{4-6}$ One more challenge is to combine the SMM behavior with others chemical, optical or physical properties such as ferroelectricity, redox-activity/conductivity, luminescence, nonlinear optics, chirality/chiroptical activity in order to open the route to more potential applications. ${ }^{7-9}$ In the specific case of chiral SMMs, the chirality can come from highly optically-active ligands such as [n] helicenes, ${ }^{10,11}$ which are organic molecules with $\pi$-conjugated helical backbone made of ortho-fused aromatic rings with configurational stability for $n \geq 5 .{ }^{12}$ Subsequently the [n]helicenes can be decorated by an electroactive unit such as organometallic, ${ }^{13}$ quinone, ${ }^{14}$ pyridinium ${ }^{15}$ and tetrathiafulvalene ${ }^{16}$ (TTF) derivatives. The latter TTF core is a well-known electroactive fragment mainly used to design conducting materials ranging from semiconductors to superconductors. ${ }^{17,18}$ Its functionalization with a plethora of accepting groups allowed the TTF-based ligands to participate in the development of fluorescence switches, ${ }^{19}$ photovoltaic cells, ${ }^{20}$ coordination of transition metals ${ }^{21}$ and finally coordination of $4 \mathrm{f}$ elements. In particular, the combination of lanthanide ions with TTF-based ligands permitted to reach new classes of multi-properties compounds with redox-active luminescent SMM behaviour. ${ }^{7,22}$ To the best of our knowledge, no chiral SMM with a redox activity easily chemically accessible in common organic solvents has been reported to date. To reach such objective, we propose i) to combine both electro-active TTF and carbo[6]helicene in a unique ligand and ii) to coordinate such ligand to magnetically anisotropic Dy ${ }^{\mathrm{III}}$ ion.
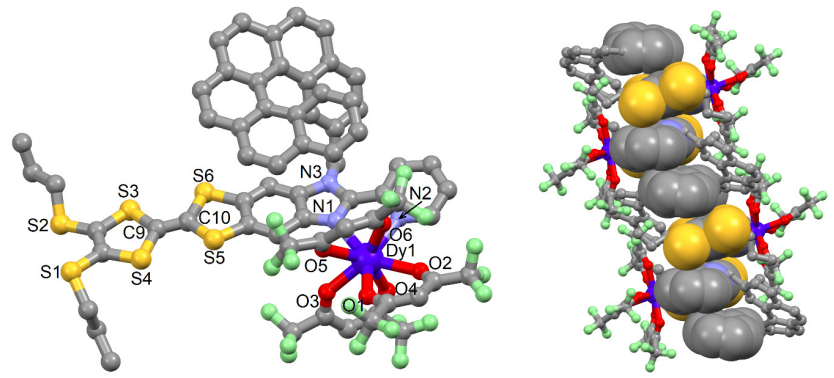

Figure 1. (Left) molecular structure of $\left[\mathrm{Dy}(\mathrm{hfac})_{3}(\mathbf{L})\right] \cdot 0.5 \mathrm{CH}_{2} \mathrm{Cl}_{2}$, the hydrogen atoms and dichloromethane molecule of crystallization were omitted for clarity. Selected bond lengths $(\AA)$ : Dy1-N1, 2.466(5); Dy1-N2, 2.562(5); Dy1-O1， 2.330(4); Dy1-O2, 2.366(4); Dy1-O3, 2.332(4); Dy1-O4, 2.351(4); Dy1-O5, 2.372(4); Dy1-O6, 2.323(4); C9-C10, 1.343(7); carbon (C, gray); fluorine $\left(\mathrm{F}\right.$, green). (Right) crystal packing of $\left[\mathrm{Dy}(\mathrm{hfac})_{3}(\mathbf{L})\right]$ highlighting the $\pi-\pi$ interactions along the $a$ axis between the TTF-based molecular skeletons and the helicenic moieties (spacefill representation).

The functionalization of the molecular skeleton 4,5bis(propylthio)-tetrathiafulvalenyl]- $1 H$-benzimidazol-2-

yl\} pyridine ${ }^{23}$ with the 2-bromomethyl[6]helicene ${ }^{24}$ in its racemic form $(85 \%$ yield, see S.I.) led to the $2-\{1-[2-$ methyl[6]helicene]4,5-[4,5-bis(propylthio)-tetrathiafulvalenyl]- $1 H$-benzimidazol-2-

yl pyridine (L) ligand which reacted with the precursor Dy $(\text { hfac })_{3} \cdot 2 \mathrm{H}_{2} \mathrm{O} \quad\left(\mathrm{hfac}^{-}=1,1,1,5,5,5\right.$-hexafluoroacetylacetonate anion) to give the mononuclear complex $\left[\mathrm{Dy}(\mathrm{hfac})_{3}(\mathbf{L})\right] \cdot 0.5 \mathrm{CH}_{2} \mathrm{Cl}_{2}$. 
Single-crystal X-ray diffraction confirms that this compound crystallizes in the triclinic space group P-1 ( $\left.\mathrm{N}^{\circ} 2\right)$ (Table $\mathrm{S} 1$ ). The molecular structure attests the success of the alkylation of the TTF-based molecular skeleton by the 2-methylenecarbo[6]helicene derivative (Figures 1 and S1). The Dy ${ }^{\text {III }}$ ion is coordinated to the bischelating $1 \mathrm{H}$-benzimidazol-2-yl $\}$ pyridine (bzip) moiety and to the three hfac ${ }^{-}$anions in a $\mathrm{N}_{2} \mathrm{O}_{6}$ surrounding. In a strict structural point of view, the first neighboring atoms create a $\mathrm{D}_{2 \mathrm{~d}}$ symmetry polyhedron (Table S2, SHAPE analysis ${ }^{25}$ ). The neutrality of the ligand $\mathbf{L}$ is confirmed by the $\mathrm{C} 9=\mathrm{C} 10$ central bond length of 1.343(7) $\AA$. The benzimidazol-tetrathiafulvalene fragment is planar while the planes formed by the benzimidazole and pyridine moieties have a twist angle of $18.0(2)^{\circ}$ resulting from the steric hindrance of the [6] helicene arm and optimized $\pi$ $\pi$ interactions between the terminal benzene ring of the helicene and the bzip coordinated fragment. A quick overview of the literature on this kind of TTF-based ligands shows a zero twist angle when no alkylation is realized (amine, $\mathrm{NH})^{26}$ and for methyl-2pyridine, ${ }^{27} \quad 4$-methylpyridine-N-oxide, ${ }^{27}$ 4,4'-dimethyl-2,2'bipyridine $^{28}$ as alkylating arms while a twist angle of $12.2(3)^{\circ}$ is measured for a bulkier arm such as 2,6-di(pyrazol-1-yl)-4methylpyridyl ${ }^{29}$. The crystal packing highlights the formation of a one-dimensional network of stacked $\mathbf{L}$ along the $a$ axis which is formed by intramolecular $\pi-\pi$ interactions between the helicene and bzip fragments and intermolecular $\pi-\pi$ interactions between two "head-to-tail" ligands (Figure 1). The shortest intermolecular Dy-Dy distance is equal to $9.529 \AA$.

The redox properties of the ligand $\mathbf{L}$ and the complex $\left[\mathrm{Dy}(\mathrm{hfac})_{3}(\mathbf{L})\right] \cdot 0.5 \mathrm{CH}_{2} \mathrm{Cl}_{2}$ are investigated by cyclic voltammetry (Figure S2, Table S3). The cyclic voltammogram for the free ligand shows two mono-electronic oxidations at $0.53 \mathrm{~V}$ for the first oxidation and $0.93 \mathrm{~V}$ for the second oxidation, corresponding to the formation of a radical cation and a dication TTF fragment, respectively. ${ }^{23,26-29}$ The coordination of the $\mathrm{Dy}(\mathrm{hfac})_{3}$ fragment has almost no significant effect on the oxidation potentials $(0.55$ $\mathrm{V}$ and $0.94 \mathrm{~V}$ ) as observed for similar compounds. ${ }^{26-29}$ The electrochemical properties attest that the reversibility of the oxidation potentials and the redox-activity of the ligand are conserved after complexation.

The temperature dependence of $\chi_{\mathrm{M}} \mathrm{T}$ for a powdered sample of $\left[\mathrm{Dy}(\mathrm{hfac})_{3}(\mathbf{L})\right] \cdot 0.5 \mathrm{CH}_{2} \mathrm{Cl}_{2}$ shows a room temperature value of $14.06 \mathrm{~cm}^{3} \mathrm{~K} \mathrm{~mol}^{-1}$ in agreement with isolated Dy ${ }^{\mathrm{III}}$ ion (Figure $2 \mathrm{a}$ ). On cooling, $\chi_{\mathrm{M}}^{\mathrm{T}}$ decreases monotonically down to $12.17 \mathrm{~cm}^{3} \mathrm{~K} \mathrm{~mol}^{-1}$ at $2 \mathrm{~K}$. The first magnetization at $2 \mathrm{~K}$ highlights a classic behavior in the field range of 0-50 kOe for such isolated Dy ${ }^{I I I}$ ion (inset Figure 2a). The same sample shows frequency dependence in zero external dc field (Figures $2 b$ and S3) but with a maximum of the $\chi_{\mathrm{M}}$ " vs. $v$ curve ( $v$ the frequency of the ac oscillating field) that falls out of the frequency range of the experimental window. The application of an external dc field cancels the Quantum Tunneling of the Magnetization (QTM) and the maximum of the $\chi_{M}$ ", vs. $v$ curve shifts to lower frequency (Figure 2b). The 1000 Oe value was chosen as the optimum field since the relaxation is slowest and more intense (Figure $2 \mathrm{~b}$ ). In such applied field, the out-of-phase component of $\chi_{\mathrm{M}}$ was observed in the temperature range of 2-8 K (Figures $2 \mathrm{c}$ and S4). The frequency dependence of the ac susceptibility can be analyzed in the framework of the extended Debye model both for field and temperature variations. The temperature dependence of the relaxation time at 1000 Oe is extracted from the extended Debye model between 2.0 and $6.0 \mathrm{~K}$ (Table S4). The Arrhenius plot of the relaxation time is well fitted by a Raman relaxation process $\tau=\mathrm{C} \times \mathrm{T}^{\mathrm{n}}$ with $\mathrm{C}=2.4(4) \times 10^{-2}$ and $\mathrm{n}=5.5(1)$ (Figure $\left.2 \mathrm{~d}\right)^{29}$. Theoretically, the expected value of the $n$ exponent for Kramers ions is 9 and can be decreased down to 4, depending on the energies of the ground state doublets. ${ }^{30,31}$ Recently is was shown that such exponent could reach a value close to 2 due to the presence of both acoustic and optic phonons in specific ligand environments. ${ }^{32}$ The Cole-Cole ${ }^{33}$ plots normalized to their isothermal value are represented in Figure S5. The Dy ${ }^{\text {III }}$ ion lies in a $\mathrm{N}_{2} \mathrm{O}_{6}$ environment with the two nitrogen atoms coming from a bischelating imidazol-2-ylpyridine derivative while the six oxygen atoms come from three $\mathrm{hfac}^{-}$anions. Thus the extracted dynamic parameters for the complex $\left[\mathrm{Dy}(\mathrm{hfac})_{3}(\mathbf{L})\right] \cdot 0.5 \mathrm{CH}_{2} \mathrm{Cl}_{2}$ can be compared with examples in which the common TTF-based skeleton is alkylated with different chemical arms.
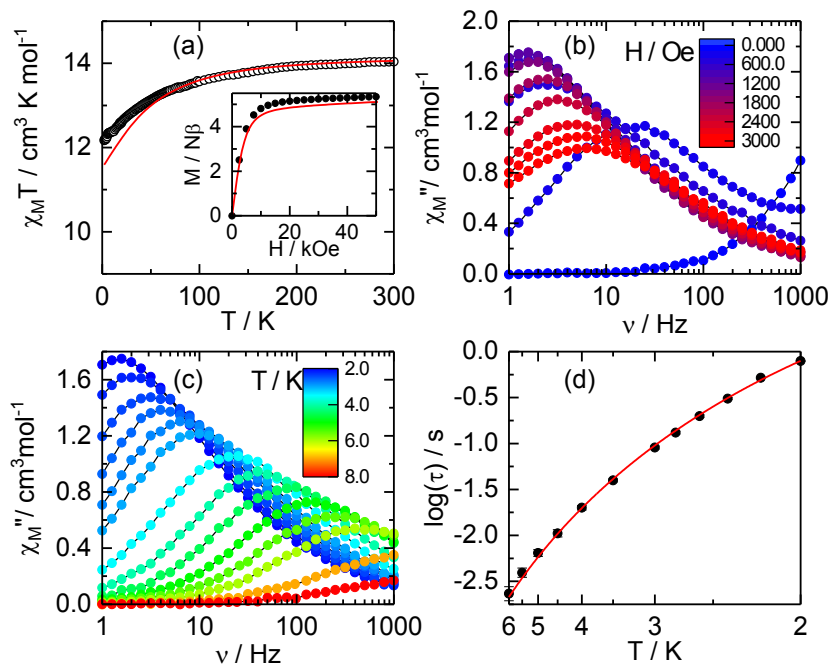

Figure 2. (a) Thermal variation of $\chi_{M} T$ for. In inset, first magnetization. Calculated curves are in red. (b) Scan field of the frequency dependence of $\chi_{M}$ '" of at $2 \mathrm{~K}$. (c) Frequency dependence of $\chi_{\mathrm{M}}$ " between 2 and $8 \mathrm{~K}$ at $1000 \mathrm{Oe}$. (d) Temperature variation of the relaxation time measured in an external field of 1000 Oe with the best-fitted curve (red line) in the temperature range of 2-6 K.

In these compounds and others of the litterature, ${ }^{34}$ the effective energy barrier range from $18 \mathrm{~K}$ to $57 \mathrm{~K}$. Nevertheless, starting from the same coordination polyhedron symmetry and $\mathrm{N}_{2} \mathrm{O}_{6}$ environment, it is clear that the nature of the alkylated group and/or the positions of the hfac anions (which can depend on the steric hindrance of the alkylated group) have a crucial importance on the value of the energy barrier. Since the complex $\left[\mathrm{Dy}(\mathrm{hfac})_{3}(\mathbf{L})\right] \cdot 0.5 \mathrm{CH}_{2} \mathrm{Cl}_{2}$ crystallizes in the triclinic P-1 space group and considering an effective spin $1 / 2$ at low temperature, the orientation of the g-tensor can be determined by measuring the magnetization of a single crystal in the three perpendicular planes (Figure S6). This oriented single crystal measurements revealed an uniaxial magnetic anisotropy with a Landé factor of 19.6 (20 expected for a pure $\mathrm{M}_{\mathrm{J}}= \pm 15 / 2$ ground state) with the orientation of the main magnetic axis along the most negatively charged direction of the coordination surrounding i.e. perpendicular to the plane containing the nitrogen atoms (Figure 3).

SA-CASSCF/SI-SO calculations were performed on $\left[\mathrm{Dy}(\mathrm{hfac})_{3}(\mathbf{L})\right]$ to rationalize the observed magnetic properties (see computational details). Energy spectra and g tensors for the eight Kramer's doublets of the ground ${ }^{6} \mathrm{H}_{15 / 2}$ multiplet of the Dy ${ }^{\text {III }}$ ion are given in Table S5. The calculations confirm the axial character of the magnetic anisotropy tensor of the ground Kramer's doublet with a large $g_{z}$ value of 19.09 for the Dy ${ }^{\text {III }}$ center and almost negligible $g_{x}$ and $g_{y}$ values. The decomposition in terms of pure $\mid J=15 / 2>$ spin wavefunctions shows that the ground state has a majority $(88 \%) \mid \pm 15 / 2>$ character with a non-negligible $(10 \%) \mid \pm 11 / 2>$ component with a first excited state lying at more than $75 \mathrm{~K}$ above the ground state. Such discrepancy with the 
hypothetic energy barrier coming from an Orbach process (21.1 $\mathrm{K})$ supports the only operative Raman relaxation process in $\left[\mathrm{Dy}(\mathrm{hfac})_{3}(\mathbf{L})\right] \cdot 0.5 \mathrm{CH}_{2} \mathrm{Cl}_{2}$. The calculated ground-state easy axis (Figure 3 ) for the Dy ${ }^{\text {III }}$ ion is oriented perpendicular to the plane formed by the \{tetrathiafulvalenyl- $1 H$-benzimidazol-2yl pyridine moiety in agreement with experiment. ${ }^{35}$
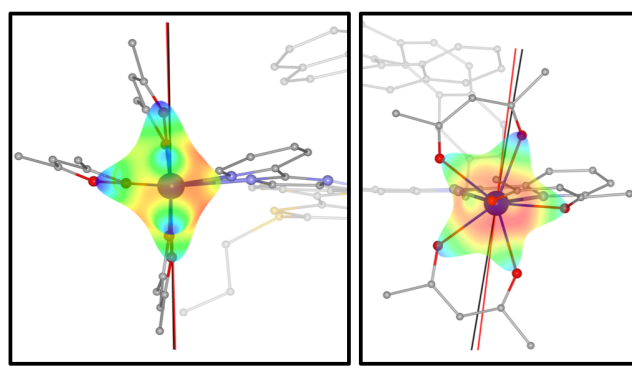

(a)

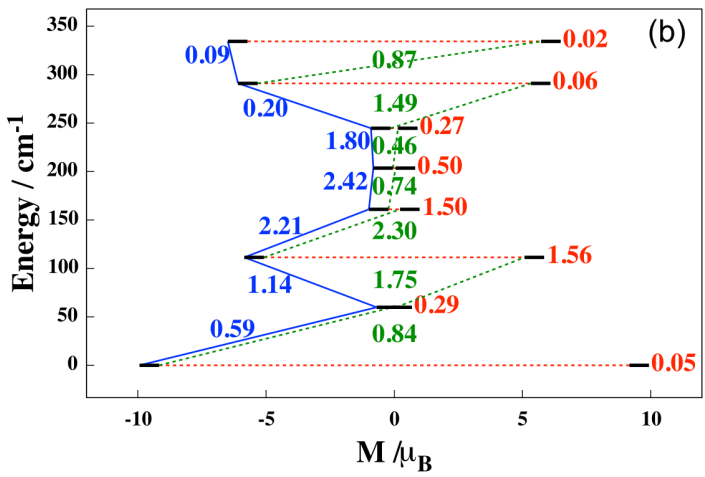

Figure 3. (a) Representation (two different orientations) of the ground state total molecular electrostatic potential around the $\mathrm{Dy}^{\mathrm{III}}$ ion. The black and red lines correspond to experimental and theoretical main anisotropy axes, respectively. (b) Computed magnetization blocking barriers. Numbers provided on each arrow are the mean absolute values for the corresponding matrix elements of the magnetic transition dipole moment.

This orientation is further supported by the representation of the molecular electrostatic potential around the Dy ${ }^{\mathrm{III}}$ ion using the home-made CAMMEL program (Calculated Molecular Multipolar Electrostatics; the description of the code is detailed in the Supporting Information). The total electrostatic potential is represented for the ground state along with both experimental and calculated axes in Figure 3a. As one can see, the most negative potential, containing the calculated magnetic axis, appears along the plane containing the two hfac ligands and perpendicular to the TTF plane. Moreover, the multipolar expansion of the total molecular electrostatic potential (Figures S7-S9) shows that quadrupolar contributions seem to be preponderant, as already observed in previous studies. ${ }^{36,37}$ Regarding the static magnetic properties, this electronic structure leads to a calculated magnetization at $2 \mathrm{~K}$ in good agreement with the experimental $\mathrm{M} v s \mathrm{H}$ and to a quantitative agreement in the thermal dependence of the $\chi_{\mathrm{M}} \mathrm{T}$ product (Figure 2), with some small discrepancy at low temperatures that may be due to possible intermolecular dipolar interactions. The computed magnetization blocking barrier is reported in Figure $3 \mathrm{~b}$. Even though main relaxation mechanisms probably involve higher excited states (up to the third), calculations also support quantum tunneling relaxation mechanisms (QTM) within the ground state doublet. However, these transition moments allow only a qualitative evaluation of the magnetization barrier, since not all contributions (e.g. spin-phonon coupling) are included. ${ }^{38-40}$
In conclusion, a redox-active chiral field-induced SMM, $\left[\mathrm{Dy}(\mathrm{hfac})_{3}(\mathbf{L})\right] \cdot 0.5 \mathrm{CH}_{2} \mathrm{Cl}_{2}$, has been successfully synthesized by combination of a redox-active TTF-based skeleton and a [6] Helicene derivative followed by the coordination reaction of the Dy(hfac) $)_{3}$ precursor. This complex exhibits field-induced SMM behavior. This compound paves the route to the redox modulation of the electronic circular dichroism ECD signal and SMM behavior. To reach such aim, the synthesis of pure enantiomers of $\left[\mathrm{Dy}(\mathrm{hfac})_{3}(\mathbf{L})\right] \cdot 0.5 \mathrm{CH}_{2} \mathrm{Cl}_{2}$ and the oxidation of $\mathbf{L}$ are in progress.

\section{ASSOCIATED CONTENT}

\section{Supporting Information}

Ortep view of $\left[\mathrm{Dy}(\mathrm{hfac})_{3}(\mathbf{L})\right] \cdot 0.5 \mathrm{CH}_{2} \mathrm{Cl}_{2}$ (Figure S1), crystallographic data (Table S1-2), cyclic voltamograms (Figure S2, Table S3), additional magnetic data (Figures S4-9 and Tables S4-5), Xray data in CIF format, experimental and material details and computational details.

This material is available free of charge via the Internet at http://pubs.acs.org."

\section{AUTHOR INFORMATION}

\section{Corresponding Author}

E-mail: fabrice.pointillart@univ-rennes1.fr

E-mail: boris.leguennic@univ-rennes1.fr

E-mail: Jeanne.crassous@univ-rennes1.fr

\section{ORCID}

Fabrice Pointillart: 0000-0001-7601-1927

Boris Le Guennic: 0000-0003-3013-0546

Jeanne Crassous: 0000-0002-4037-6067

Olivier Cador: 0000-0003-2064-6223

Ludovic Favereau 0000-0001-7847-2911

\section{Notes}

The authors declare no competing financial interests.

\section{ACKNOWLEDGMENT}

This work was supported by Région Bretagne, Rennes Métropole, CNRS, Université de Rennes 1, the ANR (ANR-13-BS07-002201) and the ERC-CoG 725184 MULTIPROSMM (project n. 725184). G.F.G. and V. M. gratefully acknowledges the European Commission through the ERC-AdG 267746 MolNanoMas (project N. 267746) and the ANR (ANR-13-BS07-0022-01) for financial support. B.L.G., G.F.G. and V.M. thank the French GENCI/IDRIS-CINES center for high-performance computing resources.

\section{REFERENCES}

(1) Guo, F.-S.; Day, B. M.; Chen, Y.-C.; Tong, M.-L.; Mansikkamäki, A.; Layfield, R. A. A Dysprosium Metallocene Single-Molecule Magnet Functioning at the Axial Limit. Angew. Chem. Int. Ed. 2017, 56, $11445-11449$

(2) Goodwin, C. A. P.; Ortu, F.; Reta, D.; Chilton, N. F.; Mills, D. P. Molecular magnetic hysteresis at 60 kelvin in dysprosocenium. Nature 2017, $548,439-442$

(3) Guo, F.-S.; Day, B. M.; Chen, Y.-C.; Tong, M.-L.; Mansikkamäki, A.; Layfield, R. A. Science 2018, DOI: 10.1126/science.aav0652

(4) Mannini, M.; Pineider, F.; Sainctavit, P.; Danieli, C.; Otero, E.; Sciancalepore, C.; Talarico, A.-M.; Arrio, M.-A.; Cornia, A.; Gatteschi, D.; Sessoli, R. Magnetic memory of a single-molecule quantum magnet wired to a gold surface. Nat. Mater. 2009, 8, 194-197. 
(5) Pedersen, K. S.; Ariciu, A.; McAdams, S.; Weihe, H.; Bendix, J.; Tuna, F.; Piligkos, S. Toward Molecular 4f Single-Ion Magnet Qubits. J. Am. Chem. Soc. 2016, 138, 5801-5804.

(6) Rocha, A. R.; García-Suarez, V. M.; Bailey, S. W.; Lambert, C. J.; Ferrer, J.; Sanvito, S. Towards Molecular Spintronics. Nat. Mater. 2005, 4, 335-339.

(7) Pointillart, F.; Le Guennic, B.; Golhen, S.; Cador, O.; Ouahab, L. Slow magnetic relaxation in radical cation tetrathiafulvalene-based lanthanide(III) dinuclear complexes. Chem. Commun. 2013, 49, 11632 11634.

(8) Long, J. Rouquette, J. Thibaud, J.-M.; Ferreira, R. A. S.; Carlos, L. D.; Donnadieu, B.; Vieru, V.; Chibotaru, L. F.; Konczewicz, L.; Haines, J.; Guari, Y.; Larionova, J. A High-Temperature Molecular Ferroelectric Zn/Dy Complex Exhibiting Single-Ion-Magnet Behavior and Lanthanide Luminescence. Angew. Chem. Int. Ed. 2015, 54, 2236-2240.

(9) Liu, C. M.; Zhang, D.-Q.; Zhu, D.-B. Field-Induced Single-Ion Magnets Based on Enantiopure Chiral $\beta$-Diketonate Ligands. Inorg. Chem. 2013, 52, 8933-8940.

(10) Ou-Yang, J.-K.; Saleh, N.; Fernandez Garcia, G.; Norel, L.; Pointillart, F.; Guizouarn, T.; Cador, O.; Totti, F.; Ouahab, L.; Crassous, J.; Le Guennic, B. Improved slow magnetic relaxation in optically pure helicene-based Dy ${ }^{\text {III }}$ single molecule magnets. Chem. Commun. 2016, 52, 14474-14477.

(11) Fernandez-Garcia, G.; Flores Gonzalez, J.; Ou-Yang, J.-K.; Saleh, N.; Pointillart, F.; Cador, O.; Guizouarn, T.; Totti, F.; Ouahab, L.; Crassous, J.; Le Guennic, B. Slow Magnetic Relaxation in Chiral Helicene-Based Coordination Complex of Dysprosium. Magnetochemistry 2017, 3, 2-13.

(12) Shen, Y.; Chen, C.-F. Helicenes Chemistry: From Synthesis to Applications, Springer, Berlin, 2017

(13) Shen, C.; Loas, G.; Srebro-Hooper, M.; Vanthuyne, N; Toupet, L.; Cador, O.; Paul, F.; Lopez Navarrete, J. T.; Ramirez, F. J.; NietoOrtega, B.; Casado, J.; Autschbach, J.; Vallet, M.; Crassous. J. Iron Alkynyl Helicenes: Redox-Triggered Chiroptical Tuning in the IR and NearIR Spectral Regions and Suitable for Telecommunications Applications. Angew. Chem. Int. Ed. 2016, 55, 8062-8066; Angew. Chem. 2016, 128 , 8194-8198.

(14) Schweinfurth, D.; Zalibera, M.; Kathan, M.; Shen, C.; Mazzolini, M.; Trapp, N.; Crassous, J.; Gescheidt, G.; Diederich, F. Helicene Quinones: Redox-Triggered Chiroptical Switching and Chiral Recognition of the Semiquinone Radical Anion Lithium Salt by Electron Nuclear Double Resonance Spectroscopy. J. Am. Chem. Soc. 2014, 136, 13045 13052.

(15) Pospíšil, L.; Bednárová, L.; Štěpánek, P.; Slavíček, P.; Vávra J.; Hromadová, M.; Dlouhá, H.; Tarábek, J.; Teplý, F. Intense Chiroptical Switching in a Dicationic Helicene-Like Derivative: Exploration of a Viologen-Type Redox Manifold of a Non-Racemic Hequat. J. Am. Chem. Soc. 2014, 136, 10826-10829.

(16) Biet, T.; Fihey, A.; Cauchy, T.; Vanthuyne, N.; Roussel, C.; Crassous, J.; Avarvari, N. Ethylenedithio-Tetrathiafulvalene-Helicenes Electroactive Helical Precursors with Switchable Chiroptical Properties. Chem. Eur. J. 2013, 19, 13160-13167.

(17) Kobayashi, H.; Kobayashi, A.; Cassoux, P. BETS as a source of molecular magnetic superconductors (BETS = bis(ethylenedithio)tetraselenafulvalene. Chem. Soc. Rev. 2000, 29, 325-333.

(18) Coronado, E.; Galan-Mascaros, J. R.; Gomez-Garcia, C. J.; Laukhin, V. Coexistence of ferromagnetism and metallic conductivity in a molecule-based layered compound. Nature 2000, 408, 447-449.

(19) Zhang, G.; Zhang, D.; Guo, X.; Zhu, D. A new RedoxFluorescence Switch Based on a Triad with Tetrathiafulvalene and Antracene Units. Org. Lett. 2004, 6(8), 1209-1212.

(20) Bendikov, M.; Wudl, F.; Perepichka, D. F. Tetrathiafulvalene, and their buckminsterfullerene derivatives: the brick and mortar of organic electronics. Chem. Rev. 2004, 104, 4891-4945.

(21) Lorcy, D.; Bellec, N.; Fourmigué, M.; Avarvari, N. Tetrathiafulvalene-based group XV ligands: synthesis, coordination chemistry and radical cation salts. Coord. Chem. Rev. 2009, 253, 1398-1438.

(22) Pointillart, F.; Le Guennic, B.; Cador, O.; Maury, O.; Ouahab, L. Lanthanide Ion and Tetrathiafulvalene-Based Ligand as a "magic"
Couple toward Luminescence, Single-Molecule Magnets, and Magnetostructural Correlations. Acc. Chem. Res. 2015, 48, 2834-2842.

(23) Wu, J.; Dupont, N.; Liu, S.-X.; Neels, A.; Hauser, A.; Decurtins, S. Imidazole-Annulated Tetrathiafulvalene Exhibiting pHTuneable Intramolecular Charge Transfer and Redox Properties. Chem. Asian J. 2009, 4, 392-399.

(24) Storch, J.; Zadny, J.; Strasak, T.; Kubala, M.; Sykora, J.; Dusek, M.; Cirkva, V.; Matejka, P.; Krbal, M.; Vacek. J. Synthesis and Characterization of a Helicene-Based Imidazolium Salt and Its Application in Organic Molecular Electronics. Chem. Eur. J. 2015, 21, 2343-2347

(25) Llunell, M.; Casanova, D.; Cirera, J.; Bofill, J. M.; Alemany, P.; Alvarez, S. S. SHAPE (version 2.1), Barcelona, 2013.

(26) Cosquer, G.; Pointillart, F.; Golhen, S.; Cador, O.; Ouahab, L. Slow Magnetic relaxation in Condensed versus Dispersed Dysprosium(III) Mononuclear Complexes. Chem. Eur. J. 2013, 19, 7895-7903.

(27) Pointillart, F.; Guizouarn, T.; Lefeuvre, B.; Golhen, S.; Cador, O.; Ouahab, L. Rational Design of a Lanthanide-Based Complex Featuring Different Single-Molecule Magnets. Chem. Eur. J. 2015, 21, 16929 16934.

(28) Speed, S.; Feng, M.; Fernandez Garcia, G.; Pointillart, F.; Lefeuvre, B.; Riobé, F.; Golhen, S.; Le Guennic, B.; Totti, F.; Guyot, Y.; Cador, O.; Maury, O.; Ouahab, L. Lanthanide complexes involving multichelating TTF-based ligands. Inorg. Chem. Front. 2017, 4, 604-617.

(29) Zadrozny, J. M.; Altanasov, M.; Bryan, A. M.; Lin, C.-Y.; Rekken, B. D.; Power, P. P.; Neese, F.; Long, J. R. Slow magnetization dynamics in a series of two-coordinate iron(II) complexes. Chem. Sci. 2013, 4, 125-138.

(30) Dekker, C.; Arts, A. F. M.; Wijn, H.W.; van Duyneveldt, A. J.; Mydosh, J. A. Activated dynamics in a two-dimensional Ising spin glass: $\mathrm{Rb}_{2} \mathrm{Cu}_{1-\mathrm{x}} \mathrm{Co}_{\mathrm{x}} \mathrm{F}_{4}$. Phys. Rev. B 1989, 40, 11243.

(31) Tang, J.; Zhang, P.; Lanthanide Single Molecule Magnets; Springer-Verlag Berlin Heidelberg, 2015.

(32) Goodwin, C. A. P.; Reta, D.; Ortu, F.; Chilton, N. F.; Mills, D. P. Synthesis and Electronic Structures of Heavy Lanthanide Metallocenium Cations. J. Am. Chem. Soc. 2017, 139, 18714-18724.

(33) Cole, K. S.; Cole, R. H. Dipersion and Absorption in Dielectrics I. Alternating Current Characteristics. J. Chem. Phys. 1941, 9, 341.

(34) Kishi, Y.; Cornet, L.; Pointillart, F.; Riobé, F.; Lefeuvre, B.; Cador, O.; Le Guennic, B.; Maury, O.; Fujiwara, H.; Ouahab, L. Luminescence and Single-Molecule Magnet Behaviour in Lanthanide Coordination Complexes Involving Benzothiazole-Based tetrathiafulvalene Ligands. Eur. J. Inorg. Chem. 2018, 458.

(35) da Cunha, T. T.; Jung, J.; Boulon, M. E.; Campo, G.; Pointillart, F.; Pereira, C. L. M.; Le Guennic, B.; Cador, O.; Bernot, K.; Pineider, F.; Golhen, S.; Ouahab. L. Magnetic Poles Determinations and Robustness of Memory Effect upon Solubilization in a Dy ${ }^{\mathrm{III}}$-Based Single Ion Magnet. J. Am. Chem. Soc. 2013, 135, 16332-16335.

(36) Zhang, K.; Montigaud, V.; Cador, O.; Li, G.-P.; Le Guennic, B.; Tang, J.; Wang, Y.-Y. Tuning Magnetic Interactions in Dy(III)4 Single-Molecule Magnets. Inorg. Chem. 2018, 57, 8550-8557.

(37) Huang, G.; Fernandez Garcia, G.; Badiane, I.; Camarra, M.; Freslon, S.; Guillou, O.; Daiguebonne, C.; Totti, F.; Cador, O.; Guizouarn T.; Le Guennic, B.; Bernot, K. Magnetic slow relaxation in a Metal Organic Framework made of chains of ferromagnetically coupled SingleMolecule Magnets Chem. Eur. J. 2018, 24, 6983-6991.

(38) Escalera-Moreno, L.; Suaud, N.; Gaita-Arino, A.; Coronado, E. Determining Key Local Vibrations in the Relaxation of Molecular Spin Qubits and Single-Molecule Magnets. J. Phys. Chem. Lett., 2017, 8, $1695-1700$.

(39) Lunghi, A.; Totti, F.; Sanvito, S.; Sessoli, R. Intra-molecular origin of the spin-phonon coupling in slow-relaxing molecular magnets. Chem. Sci., 2017, 8, 6051-6059.

(40) Lunghi, A.; Totti, F.; Sessoli, R.; Sanvito, S. The role of anharmonic phonons in under-barrier spin relaxation of single molecule magnets. Nat. Commun., 2017, 8, 1-7. 
A redox-active chiral Field-Induced Single-Molecule Magnet was achieved through the coordination reaction of the $\left[\mathrm{Dy}(\mathrm{hfac})_{3}\right]$ precursor to a ligand which combines a redox-active tetrathiafulvalene core and a chiral carbo[6]-helicene fragment. This multi-properties system was characterized using X-ray crystallography, magnetism and ab initio calculations.

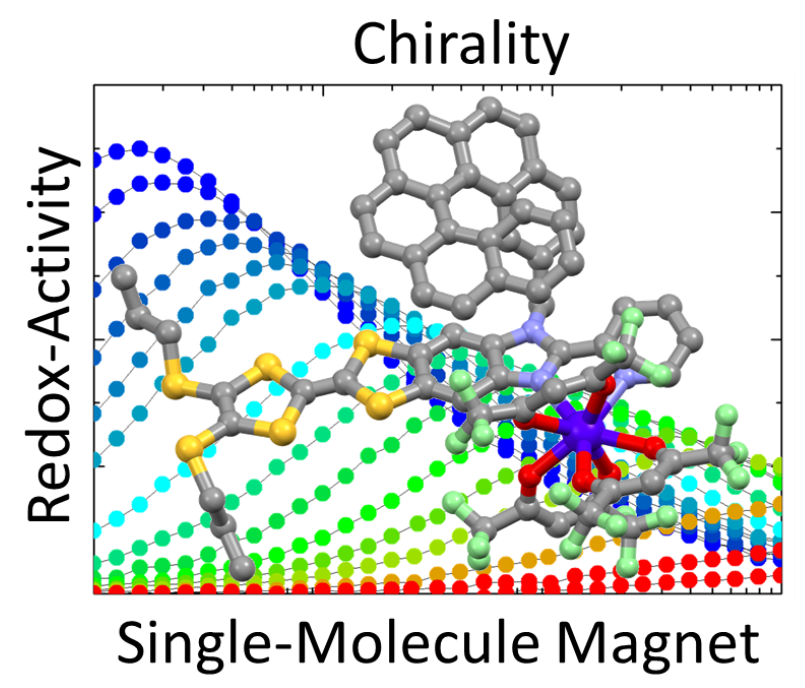

